\title{
Caballos de papel en las fiestas de Canarias
}

\author{
RICARDO MARCOS FAJARDO HERNÁNDEZ
}

En Canarias se mantienen vigentes varias danzas de caballitos de papel y queda constancia de otras muchas ya perdidas. La tradición oral sitúa su origen con el retorno de América de los emigrantes canarios; sin embargo, los referentes mediterráneos indican una procedencia europea y una vinculación a las celebraciones del Corpus Christi. La influencia francesa en Canarias podría determinar un posible origen provenzal. La polca es común en los caballitos de la isla de La Palma, en Tazacorte y Fuencaliente, mientras el sincretismo se apodera de los de El Tanque, Tenerife, con la interpretación del tajaraste, de probable adscripción aborigen. Las danzas refuerzan la identidad local pero han perdido parte de su carga simbólica ritual.

Palabras Clave: caballitos de fuego, fufos, fuscos, etnografía, Canarias

\section{Paper Horses in the Canary Islands Festivities}

In the Canary Islands many dances with paper horses are still practiced. There is record of many other dances that have been lost. The oral tradition places their origin in the return of Canary emigrants from America, nevertheless, Mediterranean references indicate a European origin that might entail to the celebrations of Corpus Christi. The French influence in the Canaries might determine a possible provenzal origin. The polka is common in the paper horse dance from the island of La Palma, Tazacorte and Fuencaliente. Syncretism gets hold of the celebrations from El Tanque, Tenerife, with the interpretation of tajaraste, aboriginal music. These dances reinforce the local identity but have lost part of their symbolic ritual load.

KEYWORDS: horses of fire, fufos, fuscos, ethnography, Canaries

\section{Ricardo Marcos Fajardo HeRnÁndez}

Departamento de Antropología-Universidad de La Laguna, San Cristóbal de La Laguna, Santa Cruz de Tenerife, Islas Canarias, España. ricardofajardo@hotmail.com 
os estudios sobre folclore, etnografía y manifestaciones festivas, con sus especificidades, precisan un cuerpo teórico que los sustente. Algunos autores del siglo XIX, como James George Frazer (1890), conciben el rito siempre inmerso en el ciclo biológico y relacionado con la supervivencia de sacrificios rituales antiguos. Emile Durkheim (2012) lo entiende como una manera de separar el tiempo sagrado del tiempo profano, un reflejo de la sociedad que fortalece sus propias estructuras, en el que tiempo y espacio son dimensiones básicas. Antropólogos como Edward Evans-Pritchard (2014) interpretan los ritos como una manera de mantener la cohesión social. Los ritos sirven para canalizar los conflictos y tensiones sociales, en opinión de Max Gluckman (Guizardi, 2012), mientras Roy Rappaport (1979) añade la importancia que tienen en el equilibrio ecológico, como adaptación al medio y a los fenómenos ambientales adversos. En España, como en los países latinoamericanos, estos estudios no parecen tener un cuerpo teórico suficiente. Joan Prat i Carós (1991: 23) señala, en relación con Cataluña, el País Vasco y Galicia, ${ }^{1}$ que muchos estudios disponen de teorías motoras en la investigación que más que científicas son políticas. En los tiempos de la dictadura del general Francisco Franco (1938-1973), los estudios de antropología en España, en especial los trabajos de campo y las consultas populares, no contaron con apoyo del régimen. En concreto, para el caso de Canarias, Fernando Estévez González (1987: 46) sostiene que "la historia de la etnografía, el folclore y la antropología canaria no es siquiera la de una antropología de la Ilustración, del romanticismo, del positivismo decimonónico o del difusionismo, sino casi exclusivamente la de sus protagonistas, la de Viera, Berthelot, Chil, Verneau, Serra".

En la medida en que no siempre se han establecido teorías, enfoques o estrategias de investigación, se dificulta hablar de una historia de la antropología canaria. Alberto García Quesada (2016) ve un antecedente en el proceso de la Ilustración del siglo XVIII y la obra de José de Viera y Clavijo (1772). En la primera mitad del siglo XX, destacan el Instituto de Estudios Canarios, la Biblioteca Canaria, la Biblioteca de Tradiciones

1 Comunidades autónomas españolas de carácter histórico. En Cataluña existen numerosas danzas de caballos de papel como los que describimos en este artículo. 


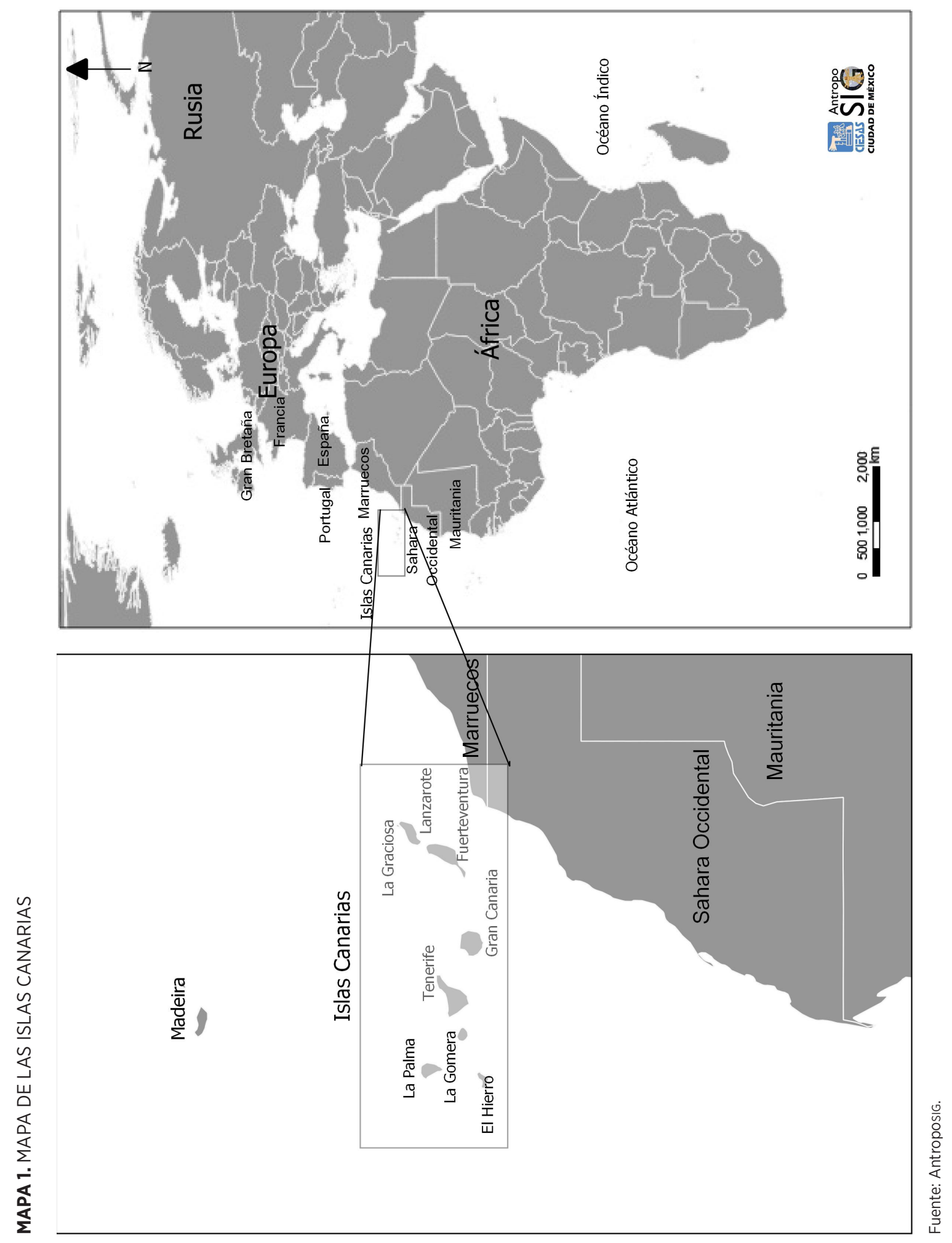


Populares y la revista Tagoro, que publicaron numerosos artículos y reseñas sobre fiestas; también los trabajos de Manuel Lorenzo Perera (1988; 1989; 1998a; 1998b; 2002), autor de numerosas monográfias y una prolífica investigación en el campo de la etnografía canaria, así como la rica investigación de Manuel Hernández González (2007).

En algunas localidades canarias, en el marco de celebraciones festivas populares, tienen aparición danzas con figuras de papel que representan caballos cabalgados por diferentes personas. Las más conocidas por su arraigo son Los Caballos Fuscos de Fuencaliente y Los Caballos Fufos de Tazacorte, en La Palma, así como Los Caballitos de Fuego de La Laguna y Los Caballitos Bailones de El Tanque, en Tenerife, aunque existen referencias a otras danzas ya desaparecidas. Los caballos se han representado en Las Libreas de Tejina, El Socorro y Tegueste; las Fiestas de El Amparo y Las Angustias, en Icod de los Vinos, y en Los Silos, San Diego y San Benito, en La Laguna; La Pandorga en la Bajada de la Virgen de Las Nieves, en Santa Cruz de La Palma, y otras. En los tres primeros casos, en Fuencaliente, Tazacorte y La Laguna, el número de figuras equinas es abundante, en general más de una veintena. Para conocer los detalles de esta actividad en el pasado, en relación con los caballos que salen en la isla de La Palma, debemos referirnos a fuentes orales, limitadas al último tercio del siglo XIX, pues la bibliografía existente es reciente. Los Caballos de Fuego de La Laguna, en la isla de Tenerife, tienen referencias bibliográficas más antiguas. La escritora inglesa Elizabeth Murray (1859: 86), quien vivió en Tenerife a mediados del siglo XIX, hizo una descripción de la fiesta de La Pandorga ${ }^{2}$ en la que aparecían caballitos de papel. También encontramos referencias a caballitos en Santa Cruz de La Palma, en el Programa de la Bajada de La Virgen de Las Nieves de 1875 (Ayuntamiento de Santa Cruz de la Palma, 1875), en el que se señala que el miércoles 7 de abril salió una "lucida Pandorga" compuesta de infinidad de caballos y otras figuras iluminadas.

\section{Cuerpo teórico y metodológico}

Hemos abarcado estas manifestaciones de las Islas Canarias y realizado una descripción detallada bajo la metodología del trabajo de campo, usual en la etnografía y la antropología cultural. Para ello nos hemos servido principalmente de la observación directa y de informantes cualificados en cada una, dada la escasa bibliografía existente. Finalmente, nos hemos servido del método comparativo afín a la antropología cultural. De este modo, dadas las similitudes, planteamos un origen común entre estas manifestaciones canarias y otras que tienen lugar en diferentes partes de América y Europa. El método comparativo exige una toma de datos cuantitativamente importante y rigurosa. El objetivo es analizar y describir cada una de las manifestaciones con figuras de caballos en su contexto festivo, social y cultural, atendiendo a su evolución histórica y dentro del ciclo anual en el que se realiza. También, hacer un análisis comparativo entre éstas y otras manifestaciones similares, en las que haya nexos culturales comunes, de manera que podamos concluir un origen común y cómo se han adaptado, con sus variaciones regionales, a su contexto actual.

Compartimos con Víctor Turner (1969) la diferencia existente entre las manifestaciones celebradas en las comunidades rurales, ligadas a la vida agraria o pastoril, y las que se celebran en comunidades urbanas. En este sentido, Turner denomina rituales a las realizadas en el mundo rural y performances a las que se llevan a cabo en entornos urbanos, en su mayoría

Celebración festiva antigua, con figurones de papel de diversas formas, casi desaparecida. 
despojadas de su significado original. Los fenómenos rituales del entorno rural tienen relación con contextos religiosos, siguen esquemas tradicionales y suponen la participación de la mayor parte de la comunidad, así como una relación con los ciclos biológicos y económicos. Según Turner, los performances se realizan en comunidades más alejadas de la vida rural, agrícola o ganadera, y forman parte del tiempo libre de los ciudadanos, que asisten por ocio, sin un claro contenido simbólico o sagrado. El enfoque simbólico propuesto por el autor conduce a entender las culturas como sistemas de símbolos y significados compartidos por la comunidad, por lo que todo fenómeno ha de ser estudiado globalmente con su estructura, y durante todo el proceso, en su contexto. Las danzas de caballitos actuales, en Canarias, pese a realizarse en espacios rurales, han perdido buena parte de su simbolismo y se presentan en el límite del performance, bajo una tenue apariencia ritual.

\section{Caballitos en Canarias, América y Europa}

En Canarias observamos manifestaciones zoolátricas en el contexto festivo, con figuras de toros, culebras, perros, demonios en forma de animal, osos, cerdos, caballitos, etc. Tras un proceso de selección, descripción detallada y argumentación teórica, centramos este artículo en las figuras de caballos. La fiesta, como objeto de estudio dentro de la vida social y cultural, requiere un análisis generalizable y riguroso desde la perspectiva metodológica. Las unidades de observación comprenden fenómenos practicados en las Islas Canarias, pero sin limitarnos a la geografía insular, pues hemos recogido información para su comparación con otros de zonas de influencia recíproca. No hemos encontrado referencias bibliográficas que señalen el origen de este tipo de celebraciones rituales en Canarias, como era de esperar; tan sólo una vaga aportación de la tradición oral que señala, para el caso de los caballitos de La Palma, un posible origen cubano. Éstos, supuestamente, fueron reproducidos por emigrantes retornados de Cuba en el siglo XIX. Este dato no encaja de ninguna manera con los resultados de nuestra investigación, que conduce a un origen europeo, aunque no se desprecia un efecto de retorno.

Celebraciones similares pueden verse en diversos lugares de América. Son muy abundantes en Centroamérica, con algún vestigio marginal en Cuba. En México, las celebraciones con caballitos de papel tienen una dimensión enorme. ${ }^{3}$ Los colonos europeos llevaron consigo estos rituales que arraigaron en las nuevas sociedades y cobraron un nuevo simbolismo al adaptarse a las nuevas circunstancias socioculturales americanas. Las danzas de caballitos de México tienen como denominador común la simbología que supone la representación de una batalla entre los conquistadores españoles y los pueblos indígenas. Estas representaciones zoolátricas muestran abundantes similitudes con las de Canarias, aunque, como sucede también en las islas, tienen diferencias en cuanto a las danzas, la música, el diseño de los caballos, el número de danzantes, la indumentaria de los jinetes y lo que portan en las manos — sables, pañuelos o látigos-. Los caballitos de México cabalgan ligeros, pues se confeccionan con materiales poco sofisticados. Los de Aramberri y Zaragoza se confeccionan con un armazón de carrizo, tela, bandas de papel de china, cuerdas y similares. En ellos se introducen los jinetes por un hueco que se hace en el lomo, llevan sombreros de palma

3

En México encontramos caballitos en múltiples celebraciones: Zacatecas, Viesca, Coahuila, San Pablo Rancho Grande, Amarilis, Tamaulipas, San Luis Potosí, Fresnillo, Derramaderos - Villa de Arista-, Nacajuca, Tabasco, Quintín Arauz Centla, Río Grande, Cieneguilla, Tecoluta, etc. Se las considera danzas antiguas, que ya se celebraban en el siglo xVI, y procedentes de España. 
adornados con vivos colores. Su música está compuesta por varios sones interpretados con violín y tambor o violín y guitarra.

Los de otros lugares son semejantes; van sujetos a los hombros del jinete por medio de correas, mientras bailan al ritmo de sones vivos y alegres en fechas variadas a lo largo y ancho de la República. Los de Tecoluta, municipio de Nacajuca, se bailan el 14 y 15 de agosto. Los de Aramberri y Zaragoza, municipios de Nuevo León, se bailan el 4 de octubre y el 12 de diciembre, en honor de San Francisco de Asís y de la Virgen de Guadalupe, con 13 caballitos y otros tantos acompañantes, además de un torito y una mula llamada Malinche, ${ }^{4}$ también confeccionados con materiales ligeros, y el viejo de la danza. En Villahermosa de Tamulté y Tamulté de las Sabanas, Tabasco, se baila el 4 de octubre. En Pastelera de Río Grande, el 14 de abril. Es interesante la Danza del Caballito Blanco, tradicional en Tabasco, que simboliza el combate entre indígenas tabasqueños y españoles en la batalla de Centla.

Los estudios rigurosos sobre los caballitos mexicanos son escasos pero en general dan por aceptado un corte europeo en las representaciones, que en muchos casos se concreta en la lucha entre conquistadores y conquistados, y la importancia de la caballería de los europeos que impactó en los pueblos indígenas. En Trajes de danzas mexicanas, de Rafael Zamarripa Castañeda y Xóchitl Medina Ortiz (2001), se resalta que en Zacatecas se conservan danzas de influencia francesa y española del siglo XVI en las que aparecen figuras de caballitos fingidos. Nuestra línea de investigación conduce a encontrar el origen de estas representaciones en el sur de Francia, donde existe una enorme tradición de este tipo de celebraciones y han sido estudiados en mayor profundidad. Zamarripa y Medina (2001) señalan que en Zacatecas, junto a los caballitos aparece un personaje montado en una mula. Resaltamos la coincidencia entre lo descrito para Nuevo León y las representaciones canarias de El Tanque, en Tenerife, y de
Tazacorte, en La Palma. En ellas se va a reproducir la aparición de una burrita.

En Europa, las celebraciones con caballitos han sido numerosas y quedan muestras de ello en la actualidad, como ocurre en algunas comunidades de España. Pese a las pérdidas de esta muestra de teatro popular, principalmente tras la Guerra Civil, muchas han permanecido y otras han sido recuperadas. Hemos de referirnos en especial a Cataluña, ${ }^{5}$ donde anualmente tenemos una buena muestra de ellas, la mayoría revivificaciones. Podríamos decir que en lo que fue la Corona de Aragón y su zona de influencia ha habido centenares de celebraciones de Caballitos. Aragón, Islas Baleares, Comunidad Valenciana y Cataluña tienen aún bastantes muestras de estas danzas, con sus diferencias naturales. Las más antiguas constatadas son las de Tarragona, que se realizan desde 1383, pero también las de Barcelona, que datan de 1426, o las conocidas de Berga, cuya celebración con caballitos se documenta en el siglo XVII. En Cataluña, a partir del siglo XV, se les relaciona constantemente con batallas entre cristianos y turcos, pero esto no se señala en los documentos relativos a fechas anteriores.

Francia mantiene vivas, dentro de su rica cultura tradicional, algunas celebraciones festivas en las comarcas del sur, y más concretamente en Provenza, donde los Caballitos han salido durante siglos. La influencia francesa en Canarias ha sido constante e importante desde la conquista y colonización. Este tipo de danzas con caballitos de cartón y papel debieron ser abundantes en los pueblos de Canarias,

Malinche -Malinalli Tenépatl- es el nombre de una mujer nahua que tradujo para los conquistadores españoles las lenguas náhuatl y maya en el primer tercio del siglo xvI. La mula es representada por una niña vestida de blanco.

$5 \quad$ La Danza de Caballos de Tarragona es la más antigua de Cataluña. Según Joan Amades (1982), data de 1383. En 1999 se conservaban 12 comparsas de Caballitos en Cataluña, y se recuperaron muchas de ellas con posterioridad. 
perdiéndose poco a poco por la cambiante actitud de la Iglesia y de la corriente ilustrada. Algunas debieron cambiar su espacio físico y temporal de celebración y readaptarse para subsistir. También hay revivificaciones, como la que se celebra en la ciudad tinerfeña de La Laguna en la actualidad, conocida como Diablos y Tarasca,${ }^{6}$ en la que aparecen las antiguas manifestaciones del Corpus y toman vida Diabletes, Danzas de Espadas, Antiguos Gremios, Danzas de Libreas, ${ }^{7}$ con sus diablos, águila, pelícano, y cómo no, caballitos de papel. ${ }^{8}$

\section{Caballos Fufos, Caballos Fuscos, Caballos de Fuego y Caballos Bailones}

En Canarias, los caballitos de papel que se representan en el contexto de sus fiestas patronales son los Fufos de Tazacorte y los Fuscos de Fuencaliente, ambos en La Palma; mientras que en Tenerife encontramos los Caballos de Fuego de La Laguna y los Caballos Bailones de El Tanque. En los cuatro casos hay muchas similitudes y algunas diferencias. La confección es básica y consiste en un armazón de materiales ligeros, cubierto de papel cartón pintado, con tiras de papel de colores vivos.

Los que danzan actualmente en Tazacorte la víspera de la festividad de San Miguel miden, de cola a belfo, aproximadamente 2.50 metros; desde la base hasta las orejas, 1.10 metros, y de ancho, 0.45 metros. También sale una jirafa de algo más de tres metros y una burrita. En Tazacorte, la música que tradicionalmente se ha interpretado es la de polcas, marchas o corridos, como las populares "Polca del barril", 9 o "Bajo dos águilas", ${ }^{10}$ además de algún pasodoble. En 1937, por iniciativa del músico Andrés Cabrera Alejo, se incorporó una adaptación del corrido "Vuela, vuela palomita", sacado de la película mexicana titulada ;Ora Ponciano!, ${ }^{11}$ con el que bailan en la actualidad, además de las otras piezas indicadas. ${ }^{12}$ En los programas de las Fiestas de San Miguel Arcángel de 1944 aparecen Los Caballos Fufos como baile tradicional, aunque en las primeras décadas del siglo xx salían en carnavales. Los Caballos Fufos van danzando con pasos largos y contrapasos, avanzan en zigzag y se cruzan con los caballos de la fila opuesta, siempre al ritmo que marca la banda municipal. Quien viste estas figuras las porta introducido en su interior por un hueco de tamaño proporcionado, de manera que queda como jinete del caballo, la burra o la jirafa, mientras desde los hombros, con tirantes de cuerda, va sujeta toda la estructura. Numerosas personas siguen tras el grupo que parte desde el ayuntamiento hacia la plaza de la iglesia, donde gira para regresar al lugar de partida en un recorrido de poco más de un kilómetro, que se realiza en algo más de hora y media.

En Fuencaliente se confeccionan de manera similar. A ambos costados del caballo se coloca la simulación de unas piernas del caballero o amazona. En los dos casos salen entre 15 y 20 caballitos,

6 Criatura mitológica en forma de dragón que se representaba en Francia y se popularizó en las fiestas de Corpus de muchas ciudades españolas, para continuar en Canarias y algunos lugares de América.

7 En Tenerife se denomina Libreas a antiguas danzas en las que músicos con tambores, castañetas y flautas hacen acompañamiento musical y una o varias figuras de diablos son quemados en las plazas durante ciertas celebraciones festivas.

8 El desfile cuenta actualmente con la colaboración del historiador Manuel Hernández González y refleja cómo fueron estas manifestaciones en el pasado de la ciudad.

9 Compuesta por el checo Jaromir Vejvoda en 1927, fue internacionalizada tras la victoria aliada en la Segunda Guerra Mundial.

10 También llamada "Bajo la doble águila”, es una marcha militar creada por Josef Wagner.

11 Dirigida por Gabriel Soria y presentada en 1936. El director mexicano recrea la vida de un torero. El filme se hizo muy popular en Canarias.

12 La polca emigra desde Europa Central, en el siglo XIX, hacia muchos lugares de América y también las Islas Canarias. El corrido, género musical mexicano del siglo XVIII, tiene relación con la polca, de origen centroeuropeo. 


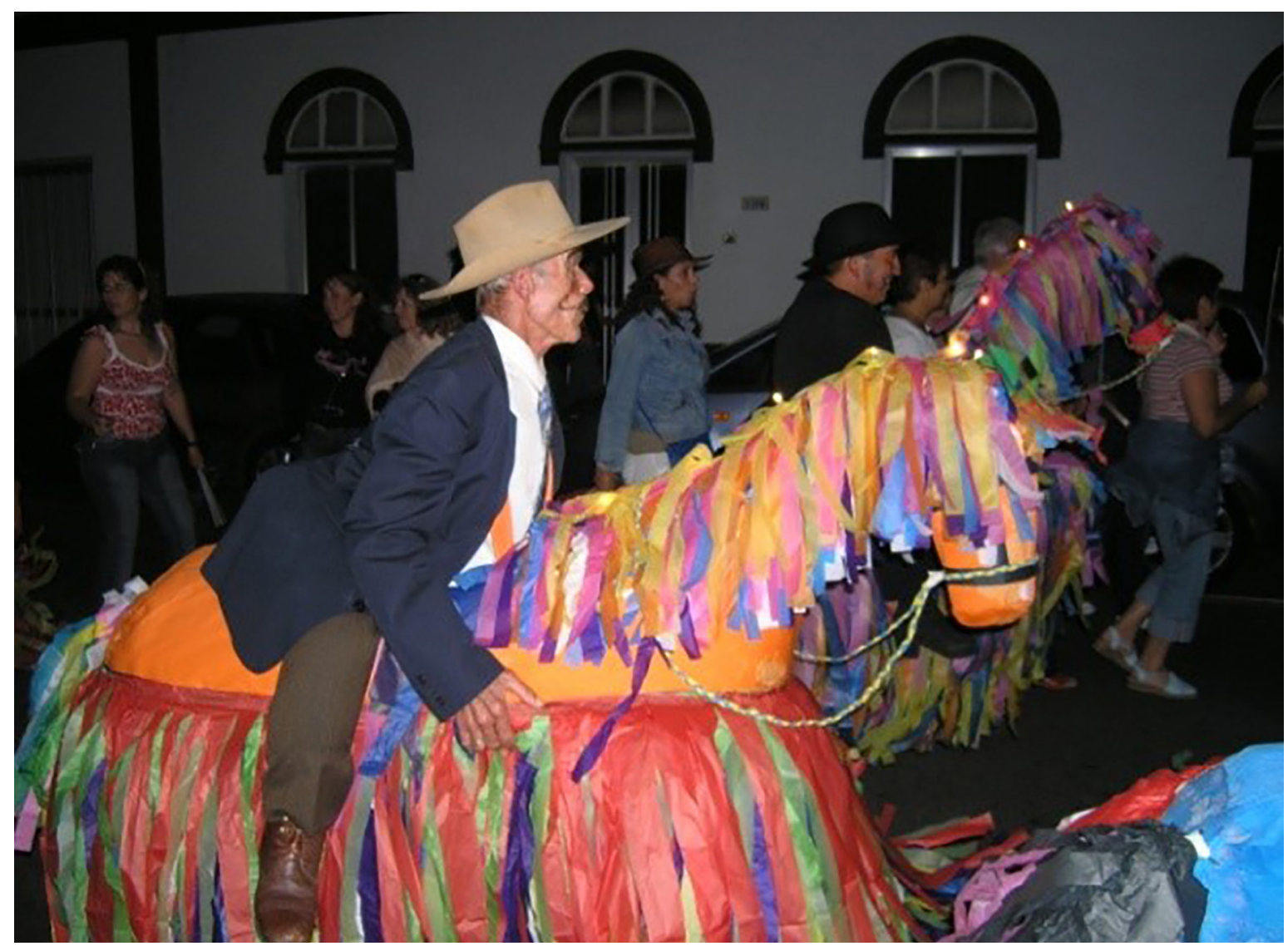

Ricardo Marcos Fajardo Hernández • Caballos Fuscos de Fuencaliente. Islas Canarias.

además de una jirafa, pero la actividad de Fuencaliente es cada dos años pares, durante la Fiesta de la Vendimia, en agosto. Los Caballos Fuscos ya se bailaban en el municipio sureño de La Palma en el último tercio del siglo XIX, en las festividades del Niño, San Antonio Abad y la Virgen del Cobre, patrona de Cuba, que los retornados hicieron patrona del barrio de Los Quemados, donde hasta finales de los años cincuenta hacían una fiesta dedicada a esta Virgen, en la que se bailaban Los Caballos Fuscos. Blas Cabrera Hernández (1846-1918) era la persona sobre la que caía el peso de la tradición de Los Caballos Fuscos a finales del siglo XIX, que danzaban a ritmo de polca: "por tradición oral sabemos que la polka de Los Caballos Fuscos ya se bailaba en la segunda mitad del siglo XIX según lo dejó dicho don Blas Cabrera Hernández fallecido en 1918” (Díaz, 1994: 426). Siguió la tradición su hijo Cornelio Cabrera, hasta su fallecimiento en 1953. Tras entrar en declive hasta perderse, fue recuperada en 1978 después de dos décadas sin actividad, aunque con cualquier acompañamiento musical. En 1988 se recuperó la música antigua gracias a la aportación de Arnulio Torres y la posterior transcripción de Julio Hernández (Poggio y Lorenzo, 2015).

En el municipio tinerfeño de El Tanque, durante la víspera del Santísimo Cristo del Calvario en el mes de octubre, Los Caballos Bailones salen con La Librea, celebración en la que unas figuras de diablos van danzando al ritmo - normalmente- de 
una pieza denominada tajaraste, de probable origen guanche. ${ }^{13}$ El tajaraste suele interpretarse con tambores y flautas en las fiestas tradicionales, aunque en El Tanque es habitual ver instrumentos variados. En la actualidad, salen tres o cuatro caballos junto a los diablos - que llevan más protagonismo-y una burrita. En la década de 1930, Salvador Hernández y sus hermanos José y Domingo - los venterossostenían esta tradición, que se perdió antes de la Guerra Civil (entrevista con Ana Emilia Carmenati, bisnieta de Salvador Hernández, El Tanque, febrero de 2011). En casa de José y en un pajar de Domingo quedaron guardados algunos caballitos, estropeados e inservibles, como referentes para su recuperación. Posteriormente, Cándido Meneses preparó La Librea con sus caballos y otras figuras. Su hija María Meneses González recuerda que él "los hizo unos cuantos años en el sótano de casa, primero los hacían los que llaman 'los venteros', después una comisión y luego mi padre. Él murió hace unos 40 años con 60 [de edad], luego mi marido también hizo los diablos y los caballos" (entrevista, El Tanque, 24 de noviembre de 2011). Antiguamente, el material empleado para el armazón era caña y mimbre. El marido de María, Román Arnoldo Martín Pérez, falleció en 1998 y ahora los hace la comisión de fiestas.

En La Laguna, el desfile transcurre el 13 de septiembre, durante las Fiestas del Santísimo Cristo, como lucía La Pandorga antigua, que se perdió en los años cincuenta y se recuperó en 1992. El número de caballos varía mucho de un año a otro, pero es de varias docenas. Algunos, de menores proporciones, son portados por niños. En el desfile se incluyen gigantes, cabezudos, personas con estandartes en forma de figuras de animales, con flecos de papel de múltiples colores, y antorchas. Una fanfarria interpreta un variado popurrí con cornetas y tambores. Al final se queman fuegos de artificio ubicados sobre el lomo, el costado y la cabeza de varios caballitos preparados de manera diferente, sin flecos ni faldellines de papel:
[Antiguamente] salían cuatro caballitos o así, nada más, y eran de papeles de flequillos y brincaban detrás de los tamborcillos en un desfile en la que iban un par de carrozas y esos caballitos locos, iban como para asustar y corrían detrás de los niños, llevaban como cohetillos, unas bengalas en la cabeza, todos llevaban fuegos y nos daban miedo (entrevista con Felicia Fajardo Delgado, La Laguna, 7 de abril de 2012).

En La Laguna aparecían caballitos en otras celebraciones. La víspera de la Fiesta de San Benito tiene lugar la procesión en la que el santo recorre las calles más cercanas a la iglesia. Hasta los años cincuenta tenía su aparición una impactante representación poco apreciada en la época. Delante de la procesión iba la Danza de San Diego, con sus cintas de colores, al son del tajaraste, y enrollándolas al palo central en su baile y en sus giros. Abría la comitiva un grupo de hombres figurando caballos. Iban con ropa oscura, a trote, a veces corriendo de adelante hacia detrás; luego en sentido inverso, haciendo cabriolas, e incluso subiéndose a las aceras atestadas de gente. En su cabeza llevaban una enorme cabeza de caballo de unos 50 o 60 centímetros, con un faldellín de color canelo oscuro que colgaba por debajo del pecho, de los hombros, y algo más abajo por la espalda. Portaban una especie de mochila asida a los hombros, con un artilugio de madera al que se asían fuegos chispeantes y cohetes sin cola que saltaban en forma incontrolada, y estallaban entre los asistentes:

Marchaban antes de la danza de las cintas con la espalda cargada de bengalas y voladores que saltaban y echaban mucho fuego. Resultaba muy llamativo porque estaba ya oscurecido y la gente huía al ver

Guanche es gentilicio de los habitantes de Tenerife antes de la conquista castellana. El término se ha generalizado para denominar a los antiguos habitantes de Canarias. 
aquello que podía quemar (entrevista con Lázaro Hernández Gutiérrez, La Laguna, 29 de diciembre de 2012).

Hacia 1959 aún salían. En la cabeza llevaban ajustada una cabeza de cartón bien grande. La gente protestaba mucho porque quemaban la ropa. A mí me quemó la chaqueta, que era la única que tenía, y me disgustó bastante porque perseguían a la gente y se arrimaban para meter miedo (entrevista con Juan Fajardo Delgado, La Laguna, 29 de diciembre de 2012).

Similares figuras de caballitos de papel o cartón hubo en otras localidades de Tenerife, como El Amparo (Lorenzo, 1989: 118) y Las Angustias (Gómez, 1997), en Icod de los Vinos, o Tejina, en La Laguna (Primo, 1976: 53). También en La Palma los caballitos fueron protagonistas en La Pandorga que se realiza durante las Fiestas Lustrales de la Bajada de la Virgen de Las Nieves (Ayuntamiento de Santa Cruz de la Palma, 1875). En el pasado no faltaban caballitos en este desfile, dentro del contexto de La Bajada, tan ligada a las celebraciones del Corpus.

\section{Prohibiciones eclesiásticas y rechazo de la llustración}

El siglo XVIII es de una explícita condena de la Iglesia contra todo tipo de manifestación teatral que se hubiera realizado en las iglesias o el contexto religioso, e incluso se perciben algunas discrepancias entre el clero y el movimiento ilustrado. Carlos III promulga una prohibición sobre los autos sacramentales en 1765 , con objeto de desterrar la superstición y desacralizar las manifestaciones teatrales. En el último tercio del siglo, la Iglesia es contraria a los bailes dentro de las iglesias y las representaciones con figuras alegóricas propias del Corpus Christi, en especial de La Tarasca, que quedó relegada en muchos lugares. Maya Ramos Smith (2002) señala que esta actividad del clero, contraria a las fiestas, produjo en la Nueva España una intensa campaña para favorecer esas reformas y marginar las escenificaciones de la religiosidad popular. Como es lógico, esto es aplicable a toda la zona de influencia de la Iglesia católica, y Canarias no es una excepción. En 1772, los Diabletes de Teguise, en la isla de Lanzarote, ven frustrada su participación en las celebraciones del Corpus de la Villa y pasan a representarse en carnavales. Todo tipo de figuras, como águilas, tarascas, dragones, diablillos, gigantes, caballitos, etc., son vistas cada vez más como una muestra de incultura y barbarie propia de las clases bajas de la sociedad, de su ignorancia y superchería. La Iglesia toma la iniciativa contra estas figuras y actividades desde mediados de ese siglo, y posteriormente responde la autoridad civil, bajo el pretexto de que suponen un problema de orden público que no tiene sentido en las procesiones religiosas, en tanto que la misma Iglesia pretende su eliminación. Recogemos las palabras de Francisco Ibarra, obispo de Caracas entre 1798 y 1806, sobre las danzas y las comedias del Corpus: "el público se lastima y ve con vergüenza un aire deshonesto y provocativo de los trajes, en el decoro, estos públicos enlaces de brazos de ambos sexos en las concurrencias de las comedias [...] viendo, cuanto menos, con indiferencia las cosas santas" (Capelán, 2010: 747). Esta dialéctica, en apariencia contradictoria, de manifestar conjuntamente el mal, representado en las figuras descritas, y el bien, deja de ser bien visto por los sectores eclesiásticos y seculares de manera cada vez más significativa, así como por los sectores económicamente dominantes de la sociedad, que pretenden su inmediata eliminación y que el culto al cuerpo de Dios sea solemne y estricto. El cabildo lagunero, en un principio, acata en forma estricta la real cédula de su majestad del 20 de febrero de 1777, según acuerdo del 2 de mayo de ese año (Hernández, 2007: 405). En 1782 no salieron los papahuevos, los matachines, los gigantes 


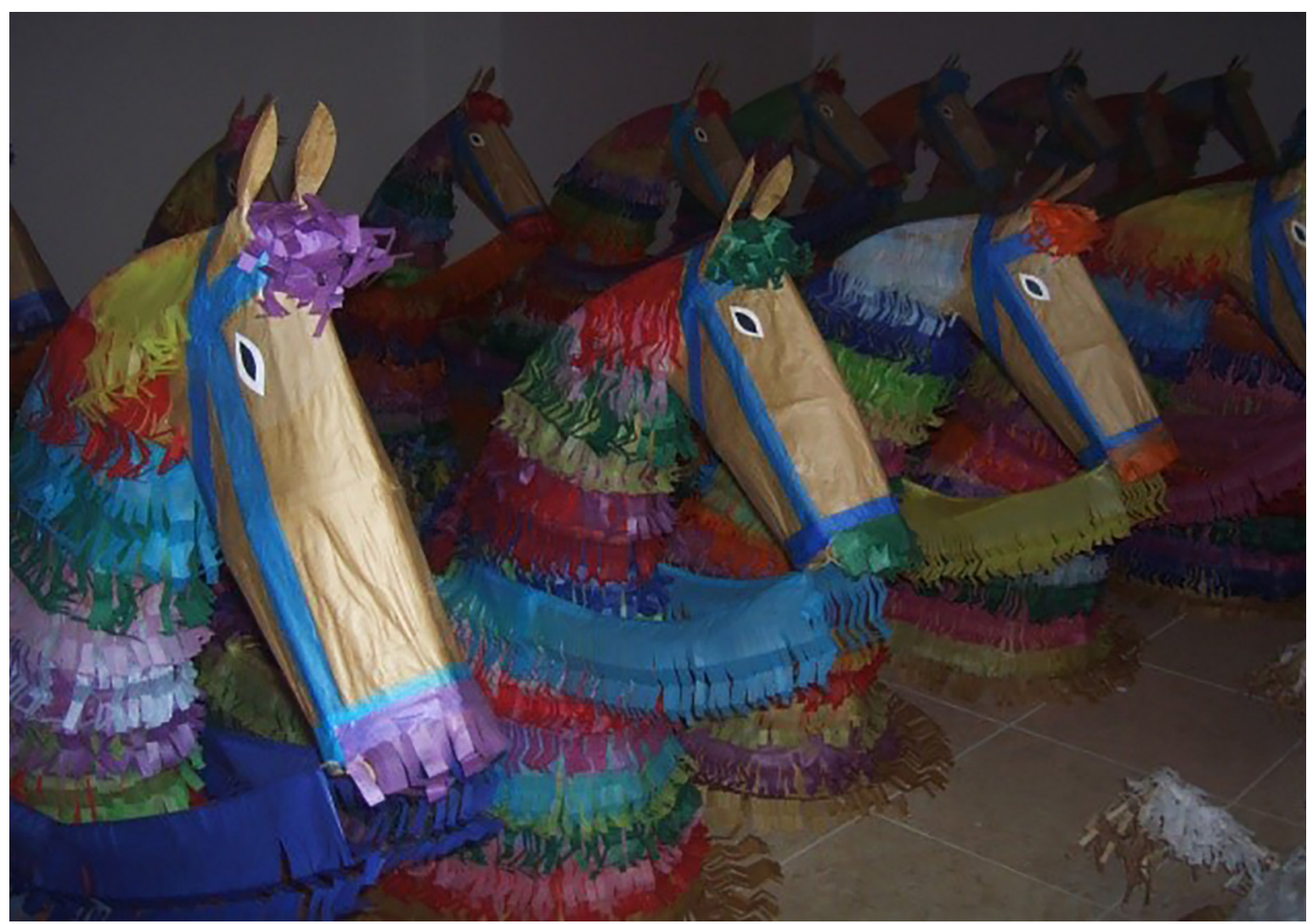

Ricardo Marcos Fajardo Hernández • Caballos Fufos de Tazacorte. Islas Canarias.

ni los diabletes. Sin embargo, la raigambre de tales muñecos es notoria en lugares como La Laguna, y aunque dejaron de participar algunos años, aprovechando que tal orden se reconvino volvieron a ser protagonistas en el Corpus Christi de la diócesis nivariense en 1817.

Los inconvenientes puestos por la Iglesia se sumaron a otros, de tipo económico, social y político. A finales del siglo XVIII, Carlos III trató de frenar esta clase de manifestaciones del Corpus Christi, por ello restó popularidad a las celebraciones que utilizaban elementos profanos, como danzas, gigantes, cabezudos, tarascas, diablillos, etc., según el antropólogo Salvador Rodríguez Becerra (2002); y en las primeras décadas del siglo XIX, se produjo un fenómeno de decadencia en numerosas fiestas, motivado por la desaparición de las estructuras que las hacían posibles debido a la Revolución liberal del primer tercio de siglo (Hernández, 2007: 171).

Las prohibiciones, la visión de las nuevas clases dominantes y la fuerte emigración fueron la causa de la desaparición de muchas representaciones en Canarias. El cambio en el modelo social, de por sí, fue determinante, pero la gran emigración que despobló el territorio rural fue un condicionante añadido que rompió la base de sustento de las danzas y éstas dejaron de representarse o continuaron en la marginalidad.

En Canarias encontramos aspectos interesantes que diferencian la fiesta de Dios respecto de otros lugares, pues el sector primario de nuestra economía participa con escenificaciones de su quehacer 
diario, de sus labores agrarias o ganaderas, "incluso mediante alegorías mitológicas" (Bethencourt, 1997: 263-293). Cuando el barroquismo dominaba los aspectos sociales y culturales, los gremios costeaban los gastos festivos. Sin embargo, bajo la Ilustración y el nuevo modelo económico, los cabildos o los regidores son los que han acarreado con los gastos de los espectáculos públicos que consideran apropiados. La sensibilidad ilustrada es menos proclive a sostener fiestas y espectáculos pues busca mayor rendimiento laboral y se afana en la supresión de actividades festivas y de ocio. Por ello es comprensible que los diferentes grupos humanos del mundo rural, que solían intervenir en celebraciones como la de Corpus, dejasen de aportar sus representaciones en los centros principales de la ciudad y regresasen a su ámbito con ellas para mantener su identidad: “en Canarias se adhieren a la fiesta las comunidades rurales participando en la ciudad o celebrando en sus respectivos pueblos" (Bethencourt, 1997: 285).

\section{Los caballitos, los ritos precristianos y el Corpus}

El origen de estas zoolatrías remite a antiguos ritos precristianos dedicados a ídolos animales invocados en ceremonias ganaderas, cuyo significado habría sido reelaborado y readaptado simbólica y significativamente por la Iglesia católica mediante la procesión religiosa del Corpus Christi, manifestación idónea en la que se aglutinaban dichos rituales, pero no como único contexto. Para algunos autores, como Albert Rumbo i Soler (2001: 42), habría que situar el origen de los caballitos en representaciones de fecundidad primitivas y cultos precristianos en honor al dios de los rebaños, o bien, en ritos de ceremonias ganaderas para alejar el mal. Este supuesto sería una adecuación simbólica realizada por la Iglesia católica en la procesión del Corpus Christi, la fiesta de mayor importancia de la cristiandad en la Edad Media. El Corpus Christi se celebró en la ciudad de La Laguna en 1497, cuando apenas había sido barrida la resistencia de los guerreros guanches en un claro proceso de aculturación.

En su estudio sobre los caballitos en los países catalanes, María Ángeles Subirats (2002: 10) señala que: "debemos buscar los orígenes de la danza en las representaciones de los grupos humanos más antiguos, en los que las actitudes de los representantes, vestidos, disfraces y movimientos nos dejan intuir la práctica de los rituales y bailes mágicos, actitudes guerreras y escenas de caza".

Además de los caballitos de Cataluña, Aragón, Comunidad Valenciana y Baleares, encontramos este entremés en otros lugares mediterráneos, como Cerdeña o Perpiñán, relacionados culturalmente con Cataluña. Los Caballitos Algodoneros de Alguer, en Cerdeña, desaparecieron a finales del siglo XVII. Formaban parte de la procesión del Corpus y su presencia reafirma los vínculos históricos entre Alguer y Cataluña. En Perpiñán, en el Roselló, el Ball de Cavallets es representado por el Ballet Joventut de Perpiñán, entidad de principios fundada en 1901. De acuerdo con Subirats (2002), los caballitos han sido representados en todo el Mediterráneo y sus orígenes se atribuyen a la representación de una batalla cuyos oponentes cambian según los tiempos y lugares, pero en términos generales suponen una lucha entre el bien y el mal. En el contexto canario y americano, la Iglesia católica necesitaba imponerse a los ritos y religiones paganas de sus aborígenes, y el simbolismo tomó una dimensión diferente.

\section{Los chivau-frus de Provenza. Influencia francesa en Canarias}

En la región de Provenza, al suroeste de Francia, los caballitos forman parte de una antiquísima tradición. Encontramos referencias sobre estas manifestaciones en la obra de Gaspard Gregoire (2009), en la 
que se describen los festejos de las fiestas del Corpus y se hace una detallada exposición sobre los llamados "chivaoux-frux". Podemos traducir esta denominación como "caballos que hacen cabriolas" o "caballos fogosos" en lengua provenzal. Otras variantes encontradas en Francia, también en Provenza, son chivaufug, chivau-frus, chivau fringants o chivau fou sous. ${ }^{14}$ Esto nos lleva a conclusiones muy diferentes a las compartidas por la creencia popular en Canarias.

Gregoire señala cómo el rey René de Anjou había establecido estos juegos en 1462 y cómo gozaban de una gran aceptación popular: "a estas alturas del desfile llegaba uno de los que gozaba de más popularidad: el de los chivau-frus. Eran unos caballos de cartón, con una abertura en el lomo que permitía al caballero que lo vestía deslizar por ella las piernas", y de esto, prosigue Gregoire, había dejado Nicolas-Claude Fabri en 1580 "unas memorias en un manuscrito curioso sobre los acontecimientos de su tiempo" (Gregoire, citado en Juana Castaño, 1988: 81).

El escuadrón de chivau-frus se componía de diez a 20 caballeros que, con espadas en la mano, simulaban combates, saltaban y bailaban al son de la música compuesta por el propio rey René, siempre con movimientos que imitaban los de los verdaderos caballos, con giros, saltos y andares característicos. Al final del desfile, las autoridades y la música de tambores y flauta entraban en la Catedral de Aix (Mistral, 1867: 23).

Todas las descripciones procedentes de fuentes antiguas que hemos hallado en Provenza sitúan a los chivau-frus en la celebración del Corpus Christi, aunque Gregoire (2009) indica que fueron establecidos por el rey René en esta festividad. Algunas fuentes relacionan esta representación con danzas rituales de cazadores de caballos salvajes desde el neolítico, y serían, por lo tanto, anteriores al Corpus, si aceptamos estas afirmaciones. La Fiesta del Corpus Christi fue instaurada por el papa Urbano IV en 1264, mediante la bula Transiturus de hoc mundo, en la que condenaba la herejía de Berengario de Tours (Urbano IV, 1264). Es muy posible que los chevaouxfrux o chevaoux-fringants sustituyeran a los caballeros que iban levantados sobre sus caballos y ejecutaban juegos de manos, pero que a consecuencia de los accidentes fueron reemplazados por hombres encajados sobre unos caballos de cartón.

Lo cierto es que los antiguos chivau-frus han sido representaciones muy extendidas en Provenza. Sin embargo, las representaciones de caballitos trascienden las riveras mediterráneas y aparecen en lugares distantes, como Canarias y algunos países de América, en especial de Centroamérica. Estas manifestaciones que encontramos en Canarias, como las de Guatemala, México o Cuba, no tienen el mismo simbolismo que las descritas en las costas del Mediterráneo. Las representaciones de Provenza no suponen una lucha contra turcos o piratas berberiscos como las que hemos visto en Cataluña o Aragón, ni contra los moros, como reinciden en la Comunidad Valenciana. En los países americanos se trueca al enemigo musulmán por batallas entre los indígenas y los conquistadores españoles, como sucede en México. La antigua representación que suponen las danzas de los caballos en todo el Mediterráneo, desde la Edad Media, ha calado en distintos lugares y se ha adaptado a sus circunstancias sociales o culturales. Al fin y al cabo, han supuesto una lucha entre el bien y el mal. Sea al representar a los caballeros cristianos contra los turcos o contra los moros, sean luchas entre indígenas americanos y conquistadores europeos, cada cultura ha aportado ricas variaciones a lo largo de siglos de representación.

Algunas canciones provenzales antiguas incluidas por el rey Renéde Anjouenel Corpus del sigloxvpuedenconsultarseen línea: <http://www.zictrad.free.fr/Provence/Cours/danses. htm\#farandole> y en <http://www.zictrad.free.fr/Provence/ Cours/Analyses/Arlesienne/analyse-arlesienne.htm>. 


\section{Conclusiones}

Los caballitos que se representan, o se han representado en el pasado, en Canarias, bien pudieron llegar de las celebraciones de Corpus Christi, incorporados muy probablemente con posterioridad a las celebraciones iniciales. Defendemos la tesis de una procedencia de corte europeo desde el Mediterráneo francés.

La conservación en Tazacorte y Fuencaliente de las denominaciones "Fufos" y "Fuscos", tan próximas fonéticamente a la designación provenzal "fus", "fux" o "frus", nos induce a mantener la tesis de su origen provenzal. La presencia de familias francesas en Canarias desde los años posteriores a la conquista es constante, y de importacia especial en La Palma. Apellidos franceses como Dugour, Porlier, Arnau, Guigou, Mustelier, La Rocha o Rocha, Massieu, Ripoche, Gourie, Ladeveze, Ascanio, Croissier, Baulen, Casalón y otros son visibles en Canarias. En el siglo XVIII, casi 20\% de los extranjeros residentes en las islas eran franceses (Suarez, 2008). La celebración lustral de la Bajada de la Virgen de las Nieves evoca manifestaciones dieciochescas y no puede esconder vinculaciones con manifestaciones propias del Corpus Christi: pandorga con farolillos, caballitos, mascarones con gigantes y cabezudos, minué de gusto versallesco, propio del rococó del siglo XVIII, carro alegórico de raíz barroca como lo es también la Danza de los Enanos. Curiosamente, el minué o festival del siglo XVIII fue presentado en la Casa Massieu por primara vez en 1945 y sustituye a una antigua danza de niños que se solía representar. El desarrollo de las plantaciones de caña de azúcar fue notable en el siglo XVI, lo que se manifiesta con la llegada a Canarias de familias pujantes, relacionadas con el comercio, procedentes de Europa - como los Massieu, originarios de Ruan-, que se asentaron en La Palma. La Casa Massieu en Tazacorte, La Palma, es de finales del siglo XVII y principios del XVIII. No debemos olvidar el origen palmero de ilustres personalidades, como Cristóbal del Hoyo Solórzano, marqués de la Villa de San Andrés y vizconde de Buen Paso, nacido en Tazacorte, en 1677, y educado en Francia (Mac Gregor, 2005: 186). También, tras la derrota de las tropas napoleónicas en Bailén, en 1809 llegaron a Santa Cruz de Tenerife 1484 prisioneros franceses y otros 500 en 1810. Éstos fueron posteriormente distribuidos en otras localidades isleñas, pues el coste de su mantenimiento y las algaradas que provocaban estos hijos de la Revolución no eran del gusto de las autoridades locales, unido al coste de su manutención. Muchos de estos franceses se establecieron en Canarias, formaron familias y es posible que hicieran que algunas de sus costumbres se arraigaran. ${ }^{15} \mathrm{El}$ asentamiento de empresarios y familias francesas no ha cesado desde la conquista de Canarias y se incrementó en el siglo XIX con la expansión del capitalismo y la Revolución industrial, pues buscaban nuevos lugares para invertir o comerciar. Diversas compañías navieras francesas vinculadas al transporte de productos agrarios tocaban asiduamente los puertos canarios de Las Palmas, Santa Cruz de La Palma o Santa Cruz de Tenerife (Suarez, 2008: 160).

Podemos concluir que estas representaciones en forma de caballitos de papel, cartón y materiales ligeros, que aún danzan en algunas fiestas canarias en Tazacorte, Fuencaliente, La Laguna o El Tanque, son pervivencias de ritos que debieron ser muy abundantes en las islas. Estos ritos debieron llegar incorporados a las manifestaciones del Corpus Christi, festividad muy arraigada en el archipiélago y que en el periodo inmediatamente posterior a la conquista se instauró para reforzar el triunfo del bien sobre la cosmovisión aborigen. No podemos afirmar que las figuras de caballitos se incorporaran

"Traslado a Canarias de prisioneros franceses". Archivo Histórico Provincial de Las Palmas, rollo 853, copia del Archivo Histórico Nacional, Madrid, fondo Estado, signatura 46D/83-187 (citado en Suarez, 2008). 
al Corpus canario tras los primeros momentos de la conquista, cuando la celebración era semejante a las de Sevilla y otras localidades andaluzas. La influencia francesa fue creciente, como queda manifiesto en los actos de las actuales Fiestas Lustrales de la Virgen de las Nieves en La Palma, con representaciones originales del Corpus. Éstas fueron perdiendo vigor por las prohibiciones de la Iglesia y el rechazo de las nuevas ideas de la Ilustración tras el siglo XVIII, poco dadas a comprender idolatrías irracionales, así como por el desmoronamiento de las estructuras sociales que las sostenían, provocado por las crisis y la pérdida de población. Solamente lograron permanecer en el tiempo, hasta la actualidad, aquellas danzas de caballitos que pudieron adaptarse a la nueva situación y arraigar en otros contextos sociales. Las prohibiciones de la diócesis canariense, en la provincia de Las Palmas, fueron más estrictas que en la diócesis nivariense de la provincia de Santa Cruz de Tenerife, donde estas manifestaciones han permanecido en lugares apartados de las grandes aglomeraciones urbanas. En el caso de la representación actual de La Laguna, se trata de una recuperación de los años noventa, aunque quedaban vestigios marginales de caballitos en festividades del entorno rural. Las denominaciones de las Danzas de Caballos de Fuencaliente y Tazacorte, Fuscos y Fufos, no tienen en castellano significación ajustable pero sí en provenzal, con significado de caballos que saltan y hacen cabriolas, que danzan. La enorme influencia francesa en Canarias a lo largo de la historia es patente y muchas familias francesas de origen provenzal se han avecindado en las islas. Consideramos un hecho la procedencia provenzal de las celebraciones de caballos de papel en La Palma, y en general en Canarias, por la enorme influencia de dicha región francesa, sin descartar otros aportes. Las Danzas de Caballitos de Canarias mantienen muchos rasgos comunes y muy pocas diferencias. D

\section{Bibliografía}

Amades, Joan, 1982, Costuari Catalá, Salvat Editores, Barcelona.

Ayuntamiento de Santa Cruz de la Palma, 1875, Programa de la Bajada de La Virgen de Las Nieves, Fondo Histórico de la Biblioteca Cervantes de la Sociedad La Cosmológica de Santa Cruz de La Palma, La Palma.

Bethencourt Massieu, Antonio de, 1997, "Fiestas reales en el setecientos en Canarias: identidades, evolución y peculiaridades", en Espacio, Tiempo y Forma, serie IV: Historia Moderna, núm. 10, pp. 263-293.

Capelán, Montserrat, 2010, "Tarasca, gigantes, diablillos y música en las celebraciones del Corpus Christi de la provincia española de Venezuela", en Eduardo Rey Tristan y Patricia Calvo González (coords.), 200 Años de Iberoamérica (1810-2010). Actas del XIV Encuentro de Latinoamericanistas Españoles, Santiago de Compostela, 15 al 18 de septiembre, Universidad de Santiago de Compostela-Servicio de Publicaciones e Intercambio Científico, Santiago de Compostela, pp. 747-741.

Castaño Ruiz, Juana, 1988, Las fiestas en la obra de Frederi Mistral, Universidad de Murcia, Murcia.

Díaz Lorenzo, Juan Carlos, 1994, Fuencaliente, historia y tradición, Ayuntamiento de Fuencaliente, Fuencaliente.

Durkheim, Emile, 2012, Las formas elementales en la vida religiosa, Fondo de Cultura Económica, México.

Estévez González, Fernando, 1987, Indigenismo, raza y evolución: el pensamiento antropológico canario (1750-1900), Museo Etnográfico Editorial, Santa Cruz de Tenerife.

Evans-Pritchard, Edward, 2014, Resúmenes de antropología de la Universidad de Buenos Aires. Disponible en línea: <http://resumenes antropologia.blogspot.com/search/label/Evans-Pritchard>.

Frazer, James George, 1890, The Golden Bough: A Study in Magic and Religion, McMillan, Londres.

García Quesada, Alberto (2016), Cultura, antropología y etnografía en Canarias, Ediciones Educativas, Tenerife. Disponible en línea: <http:// www.gobiernodecanarias.org/educacion/5/WebDGOIE/docs/0809/Innovacion/c_canaria/antropologia_cultura.pdf>.

Gómez Ravelo, Luis, 1997, Las antiguas Fiestas del Corpus y Las Libreas de Icod, VI Festival de Rescate Folclórico, Ayuntamiento de Icod de Los Vinos, Icod de los Vinos. 
Gregoire, Gaspard, 2009 [1777], Explication des cérémonies de la Fête-dieu d'Aix en Provence, Kessinger Publishing, Whitefish.

Guizardi, Menara Lube, 2012, “Conflicto, equilibrio y cambio social en la obra de Max Gluckman” en Papeles de/ CE/C, núm. 88. Disponible en línea: <https://identidadcolectiva.es/pdf/88.pdf>.

Hernández González, Manuel, 2007, Fiestas y creencias en Canarias en la Edad Moderna, Ediciones Idea, Tenerife.

Lorenzo Perera, Manuel, 1988, La tradición oral en Canarias, Centro de la Cultura Popular Canaria, Tenerife.

_ 1989, Las Fiestas de El Amparo, Colectivo Cultural Valle de Taoro, Tenerife.

1998a, Estampas etnográficas de Teno Alto, Centro de la Cultura Popular Canaria, Tenerife.

1998b, Estampas etnográficas del noroeste de Tenerife, Centro de la Cultura Popular Canaria, Tenerife.

2002, El folclore maldito de las Islas Canarias, Centro de la Cultura Popular Canaria, Tenerife.

Mac Gregor, Francis Coleman, 2005, Las Islas Canarias según su estado actual y con especial referencia a la topografía, estadística, industria, comercio y costumbres, Centro de la Cultura Popular Canaria, La Laguna.

Mistral, Frédéric, 1867, Calendau, J. Roumanille, Aviñón. Disponible en línea: <https://archive.org/details/calendaupoumono00mistgoog>.

Murray, Elizabeth, 2004, Sixteen Years of an Artist's Life in Morocco, Spain and Canary Islands, Ediciones Idea, Tenerife.

Poggio, Manuel y Belén Lorenzo, 2015, “La Danza de Los Caballos Fuscos en Fuencaliente de La Palma”, en El Pajar, Cuaderno de Etnografía Canaria, núm. 31, pp. 103-112.

Prat i Carós, Joan, 1991, Reflexiones sobre los nuevos objetos de estudio de la antropología social española, Cátedra, Madrid.

Primo de la Guerra, Juan, 1976, Diario I, 1800-1807, Cabildo de Tenerife, Tenerife.

Ramos Smith, Maya, 2002, Fiesta religiosa y cultura popular. La censura en las fiestas religiosas en los sig/os XVI, XVII y XVII. Disponible en línea: <http://www.hemisphericinstitute.org/cuaderno/censura/html/censura/censura.html>

Rappaport, Roy, 1979, Ecology, Meanings and Religión, North Atlantic Books, Berkeley.

Rodríguez Becerra, Salvador, 2002, "El Corpus en Andalucía. De fiesta del poder a fiesta de la identidad”, en G. Fernández Juárez y F. Martínez Gil, La Fiesta del Corpus Christi, Universidad de Castilla La Mancha (Colección Estudios, 84), Cuenca, pp. 383-398.

Rumbo i Soler, Albert, 2001, Balls de Turcs i Cavallets, Amalgama, Barcelona.

Suarez Bosa, Miguel, 2008, “Empresas y empresarios franceses en Canarias en el siglo xIx”, en Boletín Millares Carló, núm. 27, pp. 154-180.

Subirats, María Ángeles, 2002, "El Ball de Cavallets", en Revista de Folclore, vol. 22, núm. 253, pp. 10-22 Disponible en línea: <http://www. cervantesvirtual.com/portales/san_juan_de_la_cruz/obra/el-ball-de-cavallets-en-la-zona-denominada-paisos-catalans/>.

Urbano IV, 1264, Bula Transiturus de hoc mundo, Vaticano. Disponible en línea: <http://www.vatican.va/content/urbanus-iv/es/documents/ bulla-transiturus-de-mundo-11-aug-1264.html>.

Viera y Clavijo, José de, 1772, Noticias de la historia general de las Islas Canarias, Imprenta Blas Ramón, Madrid.

Turner, Victor, 1969, The Ritual Process, Transaction Publishers, Nueva York.

Zamarripa Castañeda, Rafael y Xóchitl Medina Ortiz, 2001, Trajes de danzas mexicanas, Universidad de Colima, Colima. Disponible en línea: <https://books.google.es/books?id=5htp8UkwZhEC\&printsec=frontcover\&hl=es\&source=gbs_ge_summary_r\&cad=0\#v=onepage\& q\&f=false $>$.

\section{Filmografía}

Soria, Gabriel (dir.), 1937, iOra Ponciano!, Gabriel Soria (prod.), México.

\section{Entrevistas}

Ana Emilia Carmenati, bisnieta de Salvador Hernández, El Tanque, febrero de 2011.

Felicia Fajardo Delgado, La Laguna, 7 de abril de 2012.

Juan Fajardo Delgado, La Laguna, 29 de diciembre de 2012.

Lázaro Hernández Gutiérrez, La Laguna, 29 de diciembre de 2012.

María Meneses González, El Tanque, 24 de noviembre de 2011. 